\title{
Reproduction in Brattleboro rats with diabetes insipidus
}

\author{
K. Boer, G. J. Boer and D. F. Swaab \\ Netherlands Institute for Brain Research. IJdijk 28, $1095 \mathrm{KJ}$ Amsterdam, The Netherlands
}

\begin{abstract}
Summary. The Brattleboro diabetes insipidus mutant is incapable of synthesizing vasopressin, but is activated in its production and release of oxytocin. In the homozygous female mutant, there were abnormally short and long oestrous cycles and reduced conception rates after mating with mutant males, a shortened gestation length, and a shorter time-course of labour. A better conception rate when mutant females were mated with normal Brattleboro males indicates the involvement of a male factor in the subfertility. The reduced litter size in diabetes insipidus rats appeared neither dependent of the male's genotype, nor due to a decreased viability of diabetes insipidus fetuses.
\end{abstract}

\section{Introduction}

Brattleboro rats homozygous for diabetes insipidus (HOM-DI) are unable to synthesize vasopressin (Valtin \& Schroeder, 1964), although the hypothalamo-neurohypophysial system shows morphological signs of increased hormone synthesis (Sokol \& Valtin, 1965; Valtin, Sawyer \& Sokol, 1965; Swaab, Boer \& Nolten, 1973) and plasma oxytocin levels indeed are 5 times higher than in normal rats (Dogterom, Van Wimersma Greidanus \& Swaab, 1977). For this reason, the Brattleboro rat not only seems suitable for the study of diabetes insipidus (Laycock, 1976), but also for studies of the involvement of neurohypophysial hormones in other physiological processes.

Reproductive disturbances in the Brattleboro rat were immediately apparent when the mutant was discovered in 1960 and they were summarized as: semi-sterility, a high incidence of fetal deaths, stillbirths, runts (Valtin \& Schroeder, 1964), early post-natal deaths, and small litter size (Saul, Garrity, Benirschke \& Valtin, 1968). The high incidence of perinatal deaths in HOM-DI Brattleboro rats did not appear to be due to cephalo-pelvic disproportion, and it has therefore been suggested that difficulties during parturition may be the causal factor (Valtin, 1967).

The present study investigated whether (a) disorders of the oestrous cycle were responsible for the subfertility in this mutant; (b) the subfertility could be attributed to male dysfunction; and (c) the moment of initiation and the course of parturition differed amongst animals which were homozygous for diabetes insipidus, heterozygous for diabetes insipidus, or homozygous normal.

\section{Materials and Methods}

Animal care and breeding. Brattleboro rats were cross-bred at the central institute for breeding of laboratory animals (TNO, Zeist, The Netherlands) to produce litters containing either homozygous diabetes insipidus (HOM-DI) and heterozygous diabetes insipidus (HET-DI) rats 
or homozygous normal (HOM-N) rats only. Discrimination between HOM-DI and HET-DI rats was carried out on the basis of water metabolism.

For the present study, females of similar genotype were caged together in groups of 5 , except during the study of the oestrous cycle when they were caged singly, and from Day 21 of pregnancy when they were housed in pairs with another female at the same stage of gestation. All rats received tap water and standard rat chow (Hope Farms, The Netherlands) ad libitum. Illumination was provided daily from 07:00 to 19:00 h. The 3 genetically different groups were matched for age, and body weights were therefore 125-175 g for HOM-DI females and 150$250 \mathrm{~g}$ for HET-DI and HOM-N females.

The stage of the oestrous cycle (Turner, 1960) or the onset of gestation was determined from assessments of vaginal smears taken every morning (09:00-11:00 h). The day on which spermatozoa were present in the vaginal smear was considered to be Day 0 of pregnancy.

Parturition. From the evening of Day 20 onwards, pregnant rats were observed continuously. During the dark period, observation was carried out in red light. The moment of expulsion and the weight of each offspring were noted. The onset of parturition was defined as the moment of birth of the first young and the time between the expulsion of consecutive young constituted a birth interval. The course of parturition was described by the duration of successive birth intervals (Boer, Lincoln \& Swaab, 1975).

Shortly after birth, the pituitary glands of the young from all HOM-DI and HET-DI rats and from some HOM-N mothers were removed for subsequent determination of vasopressin content (for procedure and assay, see Dogterom et al., 1977; Dogterom, Van Wimersma Greidanus \& De Wied, 1978; Boer, Dogterom \& Pronker, 1980).

Statistics. $\chi^{2}$-testing of differences was used for the data on the oestrous cycle, fertility, and the genetic constitution of the offspring, while a Student's $t$ test was applied to the differences in litter size. A Mann-Whitney U-test was used on the gestation length and birth interval data, and differences in gestation length independent of the covariant litter size were determined by multivariate analysis. Differences were regarded as significant at a probability level of $5 \%$.

\section{Results}

Oestrous cycle

The HOM-DI rats showed a high incidence of cycles that were shorter $(5 / 48$ cycles compared with $0 / 34$ cycles for HET-DI rats; not significant), or longer (14/48 compared with 1/34 for HET-DI rats, $P<0.001$ ) than 4 days (Table 1). Equivalent data for HOM-N rats were not available.

Table 1. Oestrous cycle lengths (days) of HOM-DI and HET-DI Brattleboro rats

\begin{tabular}{|c|c|c|c|c|c|c|c|c|c|c|c|c|c|c|c|c|c|}
\hline \multicolumn{11}{|c|}{ HOM-DI females } & \multicolumn{7}{|c|}{ HET-DI females } \\
\hline 1 & 2 & 3 & 4 & 5 & 6 & 7 & 8 & 9 & 10 & 11 & 12 & 13 & 14 & 15 & 16 & 17 & 18 \\
\hline $\begin{array}{l}5 \\
3 \\
5 \\
5\end{array}$ & $\begin{array}{l}5 \\
5 \\
5 \\
5\end{array}$ & $\begin{array}{l}4 \\
4 \\
4 \\
4\end{array}$ & $\begin{array}{l}4 \\
4 \\
4 \\
4\end{array}$ & $\begin{array}{l}4 \\
4 \\
4 \\
4\end{array}$ & $\begin{array}{l}3 \\
5 \\
3 \\
4 \\
4\end{array}$ & $\begin{array}{l}4 \\
4 \\
4 \\
3\end{array}$ & $\begin{array}{l}4 \\
4 \\
4 \\
4 \\
5\end{array}$ & $\begin{array}{l}5 \\
4 \\
5 \\
5 \\
3\end{array}$ & $\begin{array}{l}4 \\
4 \\
5 \\
5\end{array}$ & $\begin{array}{l}4 \\
4 \\
4 \\
4 \\
4\end{array}$ & $\begin{array}{l}4 \\
4 \\
4 \\
4 \\
4\end{array}$ & $\begin{array}{l}4 \\
4 \\
4 \\
4 \\
4\end{array}$ & $\begin{array}{l}4 \\
4 \\
4 \\
4 \\
4\end{array}$ & $\begin{array}{l}4 \\
4 \\
4 \\
4 \\
4\end{array}$ & $\begin{array}{l}4 \\
4 \\
4 \\
4 \\
4\end{array}$ & $\begin{array}{l}4 \\
4 \\
4 \\
4 \\
4\end{array}$ & $\begin{array}{l}4 \\
5 \\
4 \\
4\end{array}$ \\
\hline
\end{tabular}

All females mated in the first and second cycle after introduction of the males at Day 20, but Rats 1, 2, 3, 4 and 11 did not litter. 
Fertility rate

Vaginal smears revealed that 8 out of 11 HOM-DI females mated within the first oestrous cycle after the start of nightly caging with a genetically similar male. The remaining 3 HOM-DI females mated during the second cycle (Table 1). However, 5 of these HOM-DI females failed to become pregnant. In contrast, all 7 HET-DI females mated during their first oestrous cycle of exposure to males, and all became pregnant.

In a different experiment only 48 of 72 (67\%) sperm-positive HOM-DI females mated by HOM-DI males became pregnant as compared with 26 out of $27(96 \%)$ sperm-positive females mated with HOM-N males $(P<0.01)$.

\section{Litter size}

As shown in Table 2 litter size in HOM-DI rats was significantly lower than in HOM-N rats. However, in a different experiment no difference was found between the litter size of HOM-DI females mated with HOM-DI males and that of HOM-DI females mated with HOM-N males (Table 2).

Table 2. Litter size in rats of different genotype according to whether they are homozygous (HOM) or heterozygous (HET) for diabetes insipidus (DI) or normal (HOM-N)

\begin{tabular}{|c|c|c|c|}
\hline Exp. & Mating & No. of litters & Mean \pm s.e.m. litter size \\
\hline 1 & $\begin{array}{l}\text { HOM-DI } \sigma \times \text { HOM-DI } q \\
\text { HET-DI } \delta \times \text { HET-DI } q \\
\text { HOM-N } \sigma \times \text { HOM-N } q\end{array}$ & $\begin{array}{l}30 \\
23 \\
24\end{array}$ & $\begin{array}{l}7.6 \pm 0.6^{*} \\
8.9 \pm 0.8 \\
9.9 \pm 0.5^{*}\end{array}$ \\
\hline 2 & $\begin{array}{l}\text { HOM-DI } \partial \times \text { HOM-DI } q \\
\text { HOM-N } d \times \text { HOM-DI } q\end{array}$ & $\begin{array}{l}36 \\
17\end{array}$ & $\begin{array}{l}8.3 \pm 0.4 \\
8.0 \pm 0.6\end{array}$ \\
\hline
\end{tabular}

* These values are significantly different, $P<0.005$.

\section{Gestation length}

The onset of parturition was studied in 30 HOM-DI, 22 HET-DI and 23 HOM-N rats which had been mated by genetically similar males. Since there was a negative correlation between litter size and gestation length (for all 75 rats: $r=-0.43 ; P<0.01$ ) and since small litters ( $<6$ young) were more common in HOM-DI $(\mathrm{N}=7)$ and HET-DI $(\mathrm{N}=5)$ than in HOM-N $(\mathrm{N}=1)$ rats, only rats having 6 or more young were used for the data portrayed in Text-fig. 1.

Most of the animals with 6 or more fetuses gave birth on Day 22. A circadian rhythm in the pattern of delivery was apparent in HET-DI and HOM-N females with a peak in the number of births occurring at the transition period from dark to light. In the HOM-DI animals parturitions occurred during the entire dark period between Days 21 and 22, and even in the light period of Day 21. The median gestation lengths were similar for HET-DI and HOM-N rats, while the value for HOM-DI animals was shortened by more than $3.5 \mathrm{~h}$ (HOM-DI/ HET-DI: $P<0.05$; HOM-DI/HOM-N: $P<0.001$ ).

Despite the selection for litters of 6 or more young there was still a difference in the mean litter size of the three genetically different groups of rats, the value for HOM-DI rats (9.0 \pm $0.4)$ being smaller $(P<0.05)$ than that of HET-DI $(10.5 \pm 0.7)$ or HOM-N $(10.1 \pm 0.5)$ rats. However, a multivariate analysis, excluding a possible influence of the covariant litter size, and making use of all data (including those from rats with $<6$ fetuses) again revealed no difference in gestation length between HET-DI and HOM-N rats, and a significant difference between HOM-DI and HOM-N rats (Table 3). 


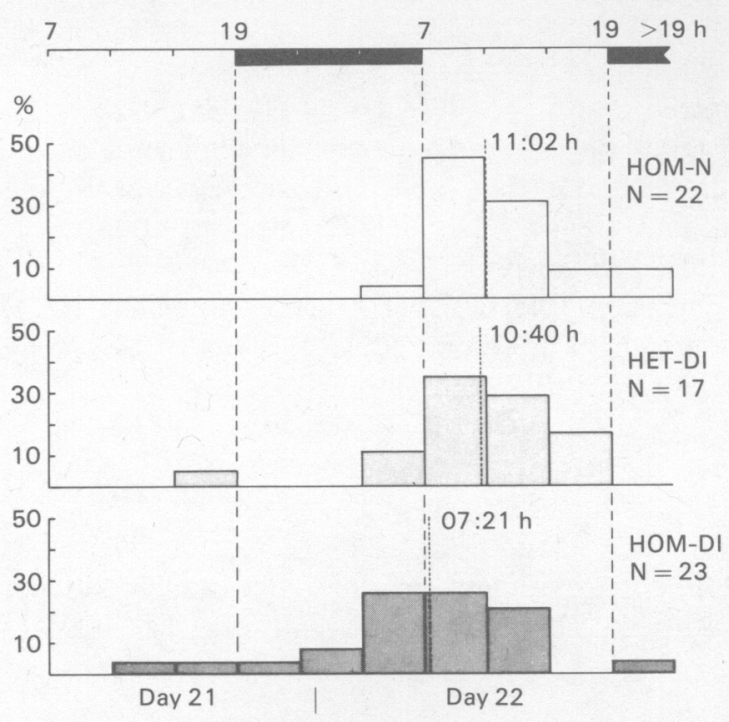

Text-fig. 1. Frequency distribution and median of gestation length (indicated by time on Day 22) in HOM-DI, HET-DI and HOM-N Brattleboro rats. The dark period of the day is indicated by the black horizontal bar at the top of the figure.

\section{Parturition}

Since small litters were not equally common in the three groups (see above), the data for rats having $<6$ young, i.e. $<5$ birth intervals, were excluded from this analysis. The frequency distribution of birth intervals (Text-fig. 2) shows a similar picture for HOM-DI rats and HET-DI rats, both having more short intefvals $(<20 \mathrm{~min})$ than did the HOM-N rats. This resulted in a medium birth interval shorter by $10 \mathrm{~min}$ in HOM-DI and HET-DI than HOM-N rats: HOM-DI 37\% shorter $(P<0.001)$ and HET-DI 32\% shorter $(P<0.001)$. Except for occasionally long birth intervals in each group of rats, usually half-way through or at the very end of parturition, this difference in the birth interval in HOM-DI and HET-DI rats was apparent throughout the parturition (Text-fig. 3).

Table 3. Gestation lengths in rats of different genotypes

\begin{tabular}{cccc}
\hline Mating & $\begin{array}{c}\text { No. of } q \% \\
\text { littering }\end{array}$ & Mean litter size & $\begin{array}{c}\text { Mean } \pm \text { s.e.m. gestation length } \\
(\min >\text { Day 22) }\end{array}$ \\
\hline HOM-DI $\% \times$ HOM-DI $\sigma^{*}$ & 30 & 7.6 & $596 \pm 118^{*}$ \\
HET-DI $\% \times$ HET-DI $\delta^{*}$ & 22 & 8.8 & $708 \pm 90$ \\
HOM-N $\$ \times$ HOM-N $\sigma^{*}$ & 23 & 9.8 & $731 \pm 64^{*}$ \\
\hline
\end{tabular}

* These values are significantly different, $P<0.01$ (multivariate analysis excluding the influence of litter size).

\section{Genetic constitution of the young}

Pituitary vasopressin assays showed that all the young from HOM-DI mothers mated by HOM-DI males lacked this hormone. None of the young from the 4 HOM-N litters that were tested lacked vasopressin $(3 \cdot 1 \mathrm{ng} \pm 0 \cdot 1, \mathrm{~N}=55)$. In the HET-DI group, 21 out of the 23 litters (192 young) were assayed for pituitary vasopressin, and $21 \%$ of the young (40) appeared to be HOM-DI. This value is not significantly different $(0.10<P<0.20)$ from the theoretically expected $25 \%$. 


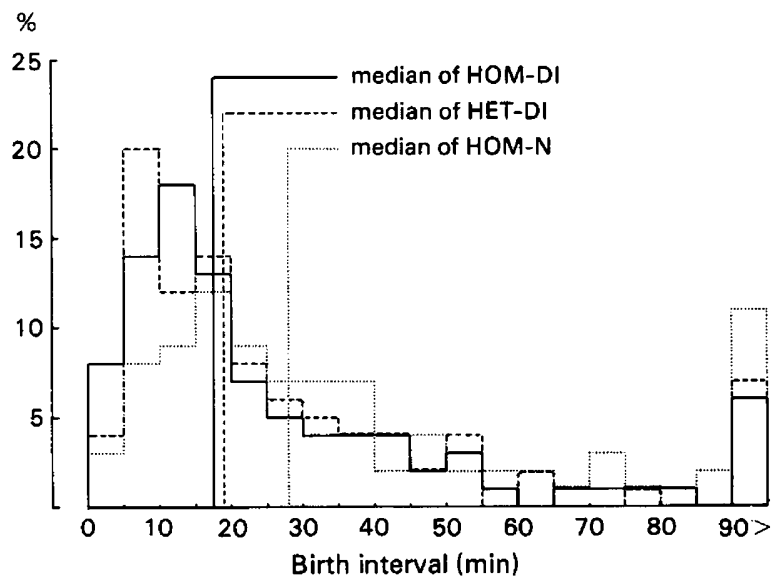

Text-fig. 2. Frequency distribution of birth intervals in HOM-DI, HET-DI and HOM-N rats, showing that the median birth interval in HOM-DI and HET-DI rats is shorter than that in HOM-N rats.

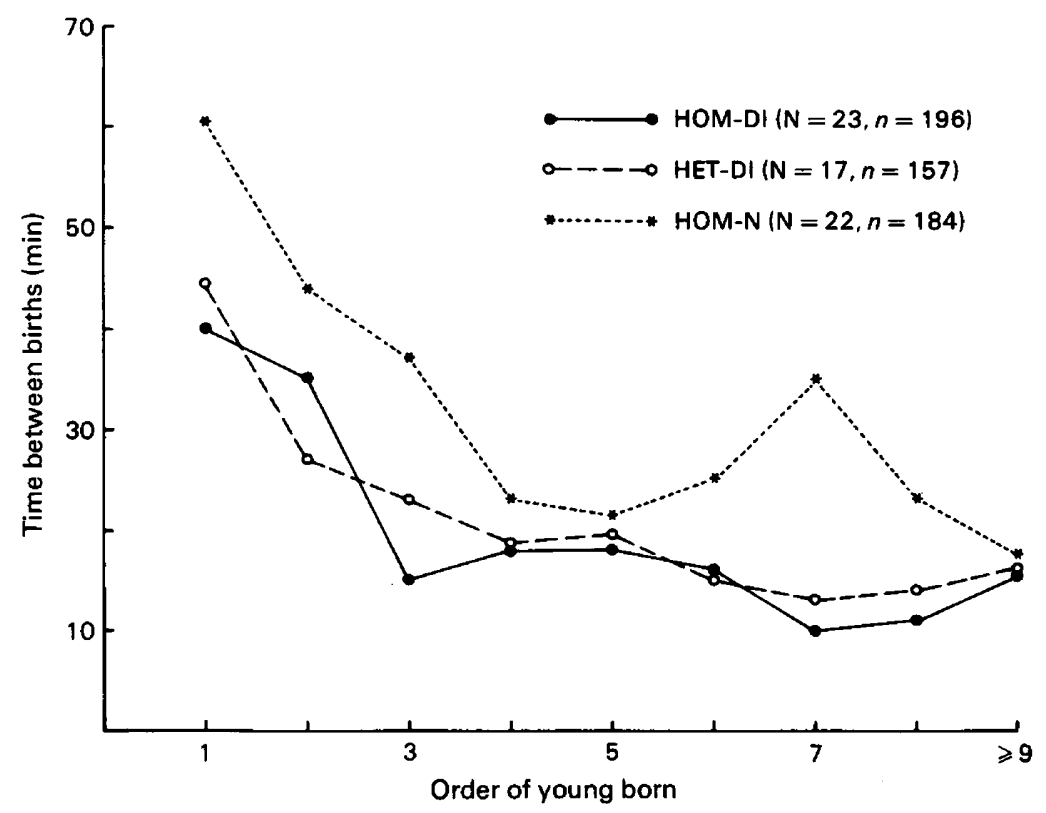

Text-fig. 3. Differences between rats of the HOM-DI, HET-DI and HOM-N genotypes for the intervals between births of young.

\section{Discussion}

In the original studies of Valtin (for review, see Valtin, 1967) pairs of HOM-DI rats usually appeared to be sterile and, if on rare occasions fertile, gave birth to a considerable proportion of still-born young or runts. Saul et al. (1968) even supposed a direct relationship between the degree of sterility, frequency of dead young or runts, and severity of diabetes insipidus. From the present study no such severe effects of hypothalamic diabetes insipidus on reproduction 
appeared, although our HOM-DI rats had a daily water intake and urine flow that equalled that of the most severely diseased animals in the study of Saul et al. (1968). It is impossible to say whether this discrepancy is due to further genetic alterations in the widely bred Brattleboro rat or to differences in husbandry (Boer, G. J. et al., 1980) and possibly developmental changes in sexual maturation (Glass, Harrison \& Swerdloff, 1976).

Whatever the reason for the general improvement in fertility may be, differences in fertility were demonstrated between HOM-DI rats and HET-DI or HOM-N rats in the present study and could be related to alterations in neurohypophysial function (see 'Introduction'). The altered cyclicity in HOM-DI females is in keeping with data for ewes (Fletcher, 1973), guineapigs (Gimeno, Borda, Rettori, Borda \& Gimeno, 1973) and rabbits (Roca et al., 1978) that show an effect of oxytocin on ovarian contractility and time of ovulation. Similar changes in the Wistar rat oestrous cycle are found during dehydration, when the release of oxytocin and vasopressin is increased (for review, see Boer, 1976).

Pregnancy in HOM-DI females was more likely when they were sperm-positive after mating with HOM-N than with HOM-DI males, although preliminary observations on sexual behaviour, using a test to sexual exhaustion, showed no differences between HOM-DI and HET-DI males in the total amount of mounts, intromissions and ejaculations (K. Boer \& N. E. Van de Poll, unpublished results). Therefore, the most likely explanation seems to be a sperm insufficiency in HOM-DI males. Decreased sperm output has been reported after longterm oxytocin treatment (rabbit: Melin, 1971; ram: Knight \& Lindsay, 1970). However, recent results (G. J. Boer, unpublished observations) obtained in a different breeding situation did not confirm this difference between HOM-DI and HOM-N males and more observations are needed to examine the factors that might be involved in the low pregnancy rate in the Brattleboro rat.

The suggestion that HOM-DI embryos are less viable than normal embryos (Saul et al., 1968) was not supported by the present data, since the proportion of HOM-DI young in a litter from HET-DI parents was not significantly different from the theoretically expected level of $25 \%$. For the same reason it seems unlikely that preferential intrauterine death of HOM-DI fetuses can account for the smaller litter size in HOM-DI females than in HET-DI and HOM-N females. The litter size was, moreover, independent of the male's genotype and consequent reproductive capabilities. Alternative explanations for the small litter size in HOM-DI rats might be increased motility of the oviduct (see Guiloff, Ibarra-Polo \& Gomez-Rogers, 1974, for man), and a disturbance of implantation (Buchanan \& Smith, 1972) due to the high oxytocin levels. Since, however, oxytocin antibodies given to pregnant rats cause reduced litter size (Kumaresan, 1974) oxytocin seems to be involved in reproduction only when given at the right time and concentration.

Pregnant HOM-DI rats started to deliver their young earlier than did HET-DI and HOM-N rats, despite the smaller litter size which usually postpones labour (Schofield, 1968; Boer, 1976). The elevation of plasma oxytocin in the DI Brattleboro seems sufficient to explain this advancement of labour, since similar effects have been obtained by oxytocin infusion (e.g. Fuchs, 1972) and electrical stimulation of neurohypophysial hormone release (Boer et al., 1975).

Elevated plasma oxytocin levels in HOM-DI females are probably also responsible for the acceleration in the course of labour observed in these animals as compared with HOM-N females. The fact that HET-DI females also gave birth more quickly, although gestation length was not shortened in HOM-DI females, is less easy to explain but could be related to a small elevation of plasma oxytocin, since vasopressin synthesis and release is known to be slightly disturbed in HET-DI rats (Miller \& Moses, 1971). Electrical stimulation of the maternal pituitary stalk resulted in an advance of the start of labour but no acceleration of the course of labour in parous rats (Boer et al., 1975) and the reverse in primigravid rats (Boer, 1976). An active role by the fetus in the course of labour (see Boer, Swaab \& Visser, 1979; Boer, K. et al., 1980) might also explain why the earlier labour in HOM-DI females occurs at the same 
velocity as labour in HET-DI females: HET-DI mothers might benefit more from the additional fetal oxytocin release than would HOM-DI females in which oxytocin levels are already markedly elevated.

In conclusion, once they are pregnant, HOM-DI Brattleboro rats do not have dramatically affected reproductive processes. Differences in fertility of the HOM-DI male, in litter size and in onset and course of labour of HOM-DI females could all be due (in part) to the concomitant higher oxytocin levels in these animals.

The present study would have been impossible without the help of the people who helped to observe labour continuously: Mr B. Fisser, in particular, and Dr J. Dogterom, Ms J. W. L. Nolten, Dr F. W. van Leeuwen and Mrs C. van Rheenen-Verberg. We thank Mr F. G. M. Snijdewint for the radioimmunoassays; Dr P. McConnell for help with the English, and Ms J. Sels for typing the manuscript. Financial support was obtained from the Foundation for Medical Research FUNGO.

\section{References}

Boer, G.J., Swaab, D.F., Uylings, H.B.M., Boer, K., Buijs, R.M. \& Velis, D.N. (1980) Neuropeptides in rat brain development. In Adaptive Capabilities of the Nervous System. Eds P. McConneil, G. J. Boer, N. E. van de Poll, H. J. Romijn \& M. A. Corner. Elsevier/North-Holland Biomedical Press, Amsterdam (in press).

Boer, K. (1976) The rat hypothalamo-neurohypophysial system: its involvement in the onset and course of labour. Medical Dissertation, University of Amsterdam, 165 pp.

Boer, K., Lincoln, D.W. \& Swaab, D.F. (1975) Effects of electrical stimulation of the neurohypophysis on labour in the rat. J. Endocr. 65, 163-176.

Boer, K., Swaab, D.F. \& Visser, M. (1979) The fetal brain and parturition. Anim. Reprod. Sci. 2, 63-75.

Boer, K., Dogterom, J. \& Pronker, H.F. (1980) The fetal rat pituitary content of oxytocin, vasopressin and a-MSH during labour. $J$. Endocr. 86, 221-229.

Buchanan, G.D. \& Smith, M.D. (1972) Effects of estrogen and oxytocin on pregnancy in the rat. Anat. Rec. 172, 280.

Dogterom, J., Van Wimersma Greidanus, Tj.B. \& Swaab, D.F. (1977) Evidence for the release of vasopressin and oxytocin into cerebrospinal fluid: measurements in plasma and CSF of intact and hypophysectomized rats. Neuroendocrinology 24, 108-118.

Dogterom, J., Van Wimersma Greidanus, Tj.B. \& De Wied, D. (1978) Vasopressin in cerebrospinal fluid of man, dog and rat. Am. J. Physiol. 234, E463-E467.

Fletcher, I.C. (1973) Effects of lactation, suckling and oxytocin on post-partum ovulation and oestrus in ewes. J. Reprod. Fert. 33, 293-298.

Fuchs, A.-R. (1972) Prostaglandin effects on rat pregnancy. I. Failure of induction of labor. Fert. Steril. 23, 410-416.

Gimeno, M.F., Borda, L.S., Rettori, V., Borda, E. \& Gimeno, A.L. (1973) In vitro contractile activity of rat and guinea pig ovaries. Effect of oxytocin and electrical stimulation. Acta physiol. latinoam. 23, 363-370.
Glass, A.R., Harrison, R. \& Swerdlofi, R.S. (1976) Effect of undernutrition and amino acid deficiency on the timing of puberty in rats. Pediat. Res. 10, 951955.

Guiloff, E., Ibarra-Polo, A.A. \& Gomez-Rogers, C. (1974) Effect of oxytocin on the contractility of the human oviduct in vivo. Fert. Steril. 25, 946-953.

Knight, T.W. \& Lindsay, D.R. (1970) Short- and long-term effects of oxytocin in quality and quantity of semen from rams. J. Reprod. Fert. 21, 523-529.

Kumaresan, P. (1974) The effect of oxytocin antibodies on the litter size in rats. Am. J. Obstet. Gynec. 118, 68-72.

Laycock, J.F. (1976) Review: The Brattleboro rat with hereditary hypothalamic diabetes insipidus as an ideal experimental model. Lab. Anim. 10, 261-270.

Melin, P. (1971) Spermatogenesis and sperm output in rabbits after long-term treatment with oxytocin. Acta endocr., Copenh. 66, 515-528.

Miller, M. \& Moses, A.M. (1971) Radioimmunoassay of urinary antidiuretic hormone with application to study of the Brattleboro rat. Endocrinology 88, 1389-1396.

Roca, R.A., Garófalo, E.G., Martino, I., Píriz, H., Rieppi, G., Marafi, M., Ohahian, C. \& Gadola, L. (1978) Effects of oxytocin antiserum and of indomethacin on hCG-induced ovulation in the rabbit. Biol. Reprod. 19, 552-557.

Saul, G.B., Garrity, E.B., Benirschke, K. \& Valtin, H. (1968) Inherited hypothalamic diabetes insipidus in the Brattleboro strain of rats. J. Hered. 59, 113-117.

Schofield, B.M. (1968) Parturition. Adv. Reprod. Physiol. 3, 9-32.

Sokol, H.W. \& Valtin, H. (1965) Morphology of the neurosecretory system in rats homozygous and heterozygous for hypothalamic diabetes insipidus (Brattleboro strain). Endocrinology 77, 692-700.

Swaab, D.F., Boer, G.J. \& Nolten, J.W.L. (1973) The hypothalamo-neurohypophysial system (HNS) of the Brattleboro rat. Acta endocr., Copenh., Suppl. 177, 80, Abstr. 
Turner, C.D. (1960) General Endocrinology, pp. 384 386. Saunders, Philadelphia.

Valtin, H. (1967) Hereditary hypothalamic diabetes insipidus in rats (Brattleboro strain). Am. J. Med. 42, 814-827.

Valtin, H. \& Schroeder, H.A. (1964) Familial hypo- thalamic diabetes insipidus in rats (Brattleboro strain). Am. J. Physiol. 206, 425-430.

Valtin, H., Sawyer, W.H. \& Sokol, H.W. (1965) Neurohypophysial principles in rats homozygous and heterozygous for hypothalamic diabetes insipidus (Brattleboro strain). Endocrinology 77, 701-706.

Received 21 January 1980 